\title{
Cross-Modal Plasticity in Deaf Child Cochlear Implant Candidates Assessed Using Visual and Somatosensory Evoked Potentials
}

\author{
Lidia E. Charroó-Ruíz MD MS, Thais Picó MD MS, María C. Pérez-Abalo, María del Carmen Hernández MD, \\ Sandra Bermejo MD, Beatriz Bermejo MD, Beatriz Álvarez MD, Antonio S. Paz MD, Ulises Rodríguez MD, \\ Manuel Sevila MD, Yesi Martínez, Lídice Galán PhD
}

\begin{abstract}
INTRODUCTION Cross-modal plasticity has been extensively studied in deaf adults with neuroimaging studies, yielding valuable results. A recent study in our laboratory with deaf-blind children found evidence of cross-modal plasticity, revealed in over-representation of median nerve somatosensory evoked potentials (SEP N20) in left hemisphere parietal, temporal and occipital regions. This finding led to asking whether SEP N20 changes are peculiar to deaf-blindness or are also present in sighted deaf children.
\end{abstract}

OBJECTIVE Assess cross-modal plasticity in deaf child cochlear implant candidates using neurophysiological techniques (visual evoked potentials and median nerve somatosensory evoked potentials).

METHODS Participants were 14 prelingually deaf children assessed in the Cuban Cochlear Implant Program. Flash visual-evoked potentials and SEP N20 were recorded at 19 scalp recording sites. Topographic maps were obtained and compared to those of control group children with normal hearing. Analysis took into account duration of hearing loss.

\section{INTRODUCTION}

Numerous publications have documented findings on crossmodal plasticity (CMP) in single sensory deprivation (either auditory or visual) from both experimental animal models and human studies.[1-12] To date, however, neuroplasticity studies of deaf persons have been carried out mainly in adults, primarily employing stimulation involving visual tasks, such as use of American Sign Language. [3,13-16] The latter has been used to study cortical activation (formation of neural networks) when communication is through sign language; notably, Neville[16] found that sign language use by deaf persons activates classic cortical areas of the left hemisphere normally linked to language acquisition and development, but that homologous right hemisphere areas are also activated.

The study of neuroplasticity, particularly in the auditory system, is an important topic; hearing is probably one of the most important human senses because of its direct link to language. However, the fact that, as a consequence of hearing loss, cortical reorganization takes place in auditory areas based on intact sensory input (visual or somatosensory), due to the effect of CMP, suggests that utility of cochlear implant $(\mathrm{Cl})$ as a treatment option for profound bilateral deafness could be adversely affected in these patients.[17]

The research presented here, evaluating cortical reorganization in deaf children using evoked potentials, builds on previous findings in our laboratory.[18] A study of a group of deaf-blind child $\mathrm{Cl}$ candidates found over-representation of the topography of somatosensory evoked potentials obtained by median nerve stimulation (SEP N20), since it had expanded to the parietal, temporal and occipital regions, which was interpreted as the first evidence
RESULTS Topographic maps of flash visual-evoked potentials did not show changes in deaf child cochlear implant candidates. However, SEP N20 from right median nerve stimulation did show changes from expansion of cortical activation into the left temporal region in deaf children aged $\geq 7$ years, which was interpreted as neurophysiological evidence of cross-modal plasticity, not previously described for this technique and type of somatosensory stimulus. We interpret this finding as due in part to duration of deafness, particularly related to handedness, since expansion was selective for the left hemisphere in the children, who were all right-handed.

CONCLUSIONS Cortical over-representation of SEP N20 in the left temporal region is interpreted as evidence of cross-modal plasticity that occurs if the deaf child does not receive a cochlear implant early in life-before concluding the critical period of neural developmentand relies on sign language for communication.

KEYWORDS Neuroplasticity, somatosensory evoked potentials, visual evoked potentials, cochlear implants, deafness, prelingual deafness, hearing loss, sensorineural hearing loss, neurophysiology, Cuba

of CMP in deaf-blind children obtained through use of this neurophysiological technique. Continuing this line of research, the present study looked at topographic maps of flash visual-evoked potentials (flash VEP) and SEP N20 in deaf child Cl candidates to assess cortical neuroplastic changes as a consequence of prelingual auditory sensory deprivation in these children and to determine whether the SEP N20 topography changes found in deaf-blind children are also found in sighted deaf children.

\section{METHODS}

A prospective study was done to assess flash VEP and SEP N20 topography in deaf children. The deaf children were selected from the Cuban Cochlear Implant Clinic in the Marfán Pediatric Teaching Hospital, where children undergo a series of required tests to determine $\mathrm{Cl}$ suitability. The sample consisted of 14 deaf children aged 5 to 15 years (mean age 9.4, SD 3.1), eight of whom were girls, who became $\mathrm{Cl}$ candidates during the first three months of 2010. Flash VEP was performed on all children, while SEP N20 was only possible for 10 of them, who were aged 5 to 15 years (mean age: 10.8, SD 3.7), four of whom were girls. Four children did not tolerate the electrical stimulus used to evoke the response. Severity of auditory sensory deprivation was clinically assessed by audiology specialists, and by auditory evoked potential techniques (transient and steady-state) of the brain stem. All children had bilateral prelingual profound sensorineural hearing loss, characterized by severity of deafness (absence of audiometric response at frequencies of $0.5,1,2$ and $4 \mathrm{kHz}$ ). None of the deaf children had vision problems.

The study also included 28 healthy children with normal hearing, aged 5 to 15 years (mean age: 10.3; SD 2.3), 12 of whom were 
girls. This control group was needed to characterize flash VEP topography in healthy children for comparison. Inclusion criteria for these children were normal audiological and ophthalmological evaluation, absence of a personal or family history of neurological or muscular disorders, no medications or drugs being taken that could affect the nervous system, and a normal physical and neurological exam.

A control group was not necessary for SEP N20, since we already had these data from a previous study.[18] All control group and deaf children were right-handed.

Flash VEP and SEP N20 The TrackWalker program was used on a digital MEDICID-4 electroencephalograph (Neuronic SA, Cuba) to record flash VEP and SEP N20, from which topographic maps of cortical responses were obtained. A monopolar recording montage was used with the 19 derivations of the 10-20 International System and a linked ear reference. Surface electrodes were used for recording, with impedances kept below $5 \mathrm{~kW}$ during the entire recording. Signals were filtered between 0.5 and $100 \mathrm{~Hz}$ for flash VEP recording and 0.5 and $300 \mathrm{~Hz}$ for SEP N20. Recordings were obtained with a sample frequency of $1000 \mathrm{~Hz}$.[18-21]

The MEDICID-4's flash stimulator was used to evoke visual responses; placed at a distance of $30 \mathrm{~cm}$ from the child's face, it presented flashes of light at a frequency of $1 \mathrm{~Hz}$. The children kept their eyes closed during stimulus presentation and binocular stimulation was used. To evoke somatosensory responses, the median nerve was stimulated on both sides separately with a Neuropack 2 electrical stimulator (Nihon Kohden Corporation, Japan), coupled to the MEDICID-4. The ground electrode, a Velcro-covered metal band, was placed around the middle third of the arm. The stimulating bar electrode was placed on the wrist for stimulation of the median nerve with the most proximal cathode. Electrical stimulus duration was $9.1 \mathrm{~ms}$ at a frequency of 3 $\mathrm{Hz}$. Intensity was gradually increased until there was clearly perceived movement of the thumb.[19] Each nerve was stimulated for 10 minutes.

All recordings were made in a room with low ambient noise and controlled temperature (never below $24^{\circ} \mathrm{C}$ ). Body temperature was taken during recording. None of the children presented fever or hypothermia. During the procedures, children rested in a supine position with eyes closed, as relaxed as possible.

Flash VEP and SEP N20 assessment Brain electrical activity recordings were assessed offline to extract flash VEP and SEP N20 and thus assess P1 and N20 components of cortical response. Evoked responses were edited with the EP WorkStation[22] program that runs on the digital MEDICID-4 electroencephalograph. Brain electrical activity segments synchronized with the stimulus, free of artifacts, were selected by visual inspection. Segments were recorded starting 20 ms pre-stimulus; evoked signals were plotted in analysis windows for a total time of $420 \mathrm{~ms}$ and $70 \mathrm{~ms}$ for flash VEP and SEP N20, respectively. These electrical activity segments were averaged to obtain flash VEP (300 windows) and SEP N20 (1000 windows). Subsequently, all head recording sites were assessed by visual inspection to identify and describe the derivations where P1 (VEP) and N20 (SEP) cortical response was present, their morphology assessed in relation to the normative studies done in our laboratories for the different types of evoked potentials and also described in the literature.
$[20,23]$ Evoked potential morphology is a qualitative parameter defined by the appearance of the peaks or waves that characterize the voltage changes in the responses evoked. In this case, evoked potentials were generated by flash and electrical stimuli, and their waves labeled according to their polarity and latency of appearance: P1 for flash VEP and N20 for SEP. Evoked potential morphology reflects the degree of synchrony and orientation of the generating dipoles participating in the responses. Additionally, P1 and N20 amplitude was measured from baseline to the maximum voltage point for each peak.

Topographic maps were obtained for each individual flash VEP and SEP N20 recording, along with average maps for each type of evoked potential, bilaterally and for both deaf and control groups. These were plotted using a peak percent scale in which $50 \%$ of the value of the maximum amplitude among all derivations is taken as the maximum value of the scale, using the pertinent analysis option in EP WorkStation.[22] In analysis of the average maps, each age group was subdivided, with age seven years as the cutoff point, which considers possible differences that take place as a result of auditory deprivation during the critical period of neural development and neuroplasticity.

To compare flash VEP and SEP N20 topography between the two groups of children (deaf children and controls), a nonparametric permutation test was used with the Student t test,[24] available in the EP-WorkStation editor module.[22] The statistical hypothesis was that the mean amplitude vectors (signal voltage) for each derivation in the flash VEP and SEP N20 recordings would be significantly different between the two groups. One thousand permutations were done in 130-150 ms and 35-45 ms poststimulus time intervals for flash VEP and SEP N20 recordings, using a significance threshold of $p \leq 0.05$. Next, topographic maps were assessed comparing deafness duration of $<7$ years versus $\geq 7$ years, measured from time of onset to age at the time of the study.

Ethical considerations Parents or guardians provided written informed consent for the children's participation. The study was approved by the ethics committees of the Marfán Pediatric Teaching Hospital and the Cuban Neuroscience Center.

\section{RESULTS}

Flash VEP topography Figure 1a shows flash VEP in a healthy, normal-hearing child from the control group. Observe the replicability of the recording, an expression of good signal-noise ratio, and the typical morphology of the P1 peak corresponding to occipital cortex activation from flash stimulation. Characteristics of this response in deaf children were comparable to that of control group children, as can be seen in Figure 1b, which shows recordings for one of the deaf children.

Figure 2a shows flash VEP topographic maps of deaf and control children. Both groups showed a similar topographic pattern flash VEP, circumscribed to the occipital region bilaterally, in children in both age groups, showing a tendency toward greater energy in the right hemisphere based on visual inspection. Considering that flash VEP topographic maps did not show differences by age, a proxy for duration of deafness, we proceeded to compute average maps for all children in both groups. Figure $2 b$ shows these maps as well as results of statistical topographic comparison in deaf children and the control group using a permutation test. Overall 
Figure 1: Flash VEP of a control group child (a) and a deaf child (b)

(a) Control

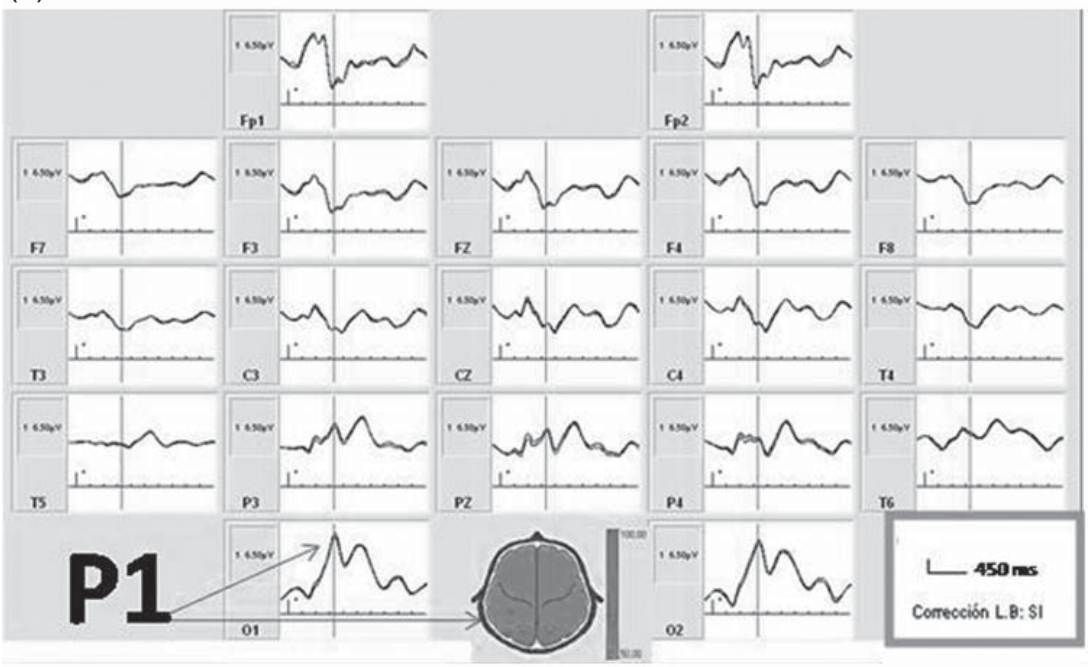

(b) Deaf child

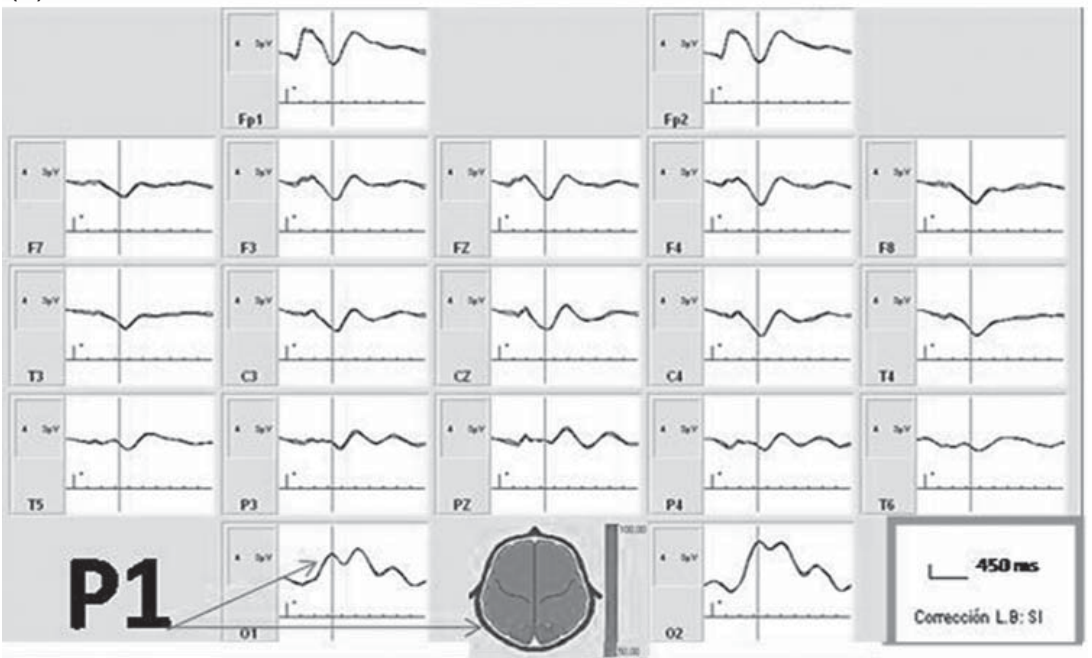

(available in color online at www.medicc.org/mediccreview/charroo-cross-modal.html)

probability ( $p=0.52)$ and by channel was not statistically significant when comparing topography of the occipital cortex evoked response from flash presentation in deaf children and the control group.

Table 1 shows flash VEP P1 peak amplitude values for deaf children and the control group. A comparison of the two groups' evoked response amplitude - that is, the energy of brain electrical activity expressed as voltage in the occipital region-found no statistically significant differences for either right or left hemisphere.

Changes in SEP N20 topography in deaf child Cl candidates as an expression of CMP Figure 3 shows the somatosensory cortical response obtained from electrical stimulation of the right median nerve in a deaf child. This recording illustrates the quality of the studies, characterized by the extent of replicability between the subaverages and typical morphology, which made the N20 peak (SEP N20) readily identifiable. Typical response morphology, present in derivation $\mathrm{C} 3$, is pointed out with arrows, on both the signals and in the map in the figure's upper left-hand corner.
Figure 4A shows average SEP N20 topographic maps obtained from median nerve electrical stimulation in deaf children. Note that in children aged $<7$ years, and therefore with fewer than seven years of deafness, SEP N20 in the left and right hemispheres corresponding to right and left median nerve stimulation, respectively, show topography focalized in the region that corresponds to the hand representation area in the primary somatosensory cortex. In contrast, in deaf children aged $\geq 7$ years, whose deafness is therefore of greater duration, evoked response from right and left median nerve stimulation shows differences in topography: the extensive response is the one evoked in the left hemisphere from right median nerve stimulation (different topography from control group map), appearing to expand into the temporal region. Statistical comparison of SEP N20 topographic maps of deaf children aged $\geq 7$ years with the control group are shown in Figure $4 \mathrm{~B}$. Overall probability was not significant $(0.69)$, but analysis by recording channel found marginal significance for the T3 recording site.

\section{DISCUSSION}

This study expands the body of evidence on neuroplasticity in deaf persons, particularly children, about whom fewer CMP studies have been published. Our SEP topographic maps in deaf child $\mathrm{Cl}$ candidates showed that flash, as a simple visual stimulus not requiring attention, did not activate auditory cortical areas deprived of their corresponding sensory input. In contrast, SEP N20 evoked by right median nerve stimulation showed cortical activation expanding into the left temporal region in deaf children aged $\geq 7$ years, which we interpret as evidence of CMP.

In deaf children, the flash VEP topographic map showed an activation pattern circumscribed to the occipital region, identical to the activation pattern of hearing children, unlike Neville's findings in the early 1980s.[5] That pioneering paper on neuroplasticity in deaf subjects, also using VEP, reported larger-amplitude response in deaf than in normal-hearing subjects. Neville and Lawson[6] replicated these findings in a later study that compared VEP response amplitude and latency in deaf subjects who used sign language to communicate from very early ages. The authors found that presentation of moving visual stimuli generated a larger-amplitude response when the moving stimulus appeared in the peripheral visual field, but not when the stimulus appeared in the center of the visual field. These effects were not present in normal-hearing subjects.[6]

With the advent of modern imaging techniques, our group and other researchers have expanded the literature based on new studies. Authors using functional magnetic resonance imaging (fMRI) have found that visual stimuli activate the auditory cortex. $[3,4]$ However, in our study, deaf children showed only occipital activation in response to flash stimulation. We believe that this finding in no way contradicts the reported findings of Neville[5] and other authors on the use of fMRI, since their studies used visual stimuli involving performance of selective visual attention tasks, such as use of sign language or presentation of a pattern of 
Figure 2: Average flash VEP topographic maps (a) and results of permutation test of deaf and control children (b) Control Group Deaf Children

(a) Children aged
$<7$ years

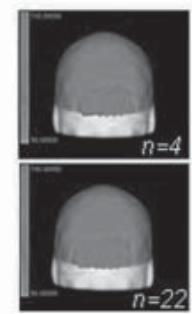

Children aged $\geq 7$ years

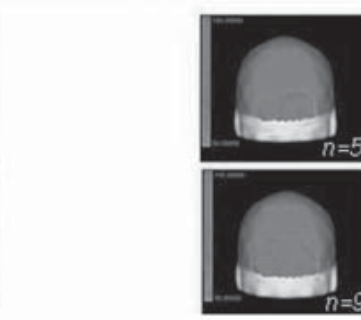

(b)
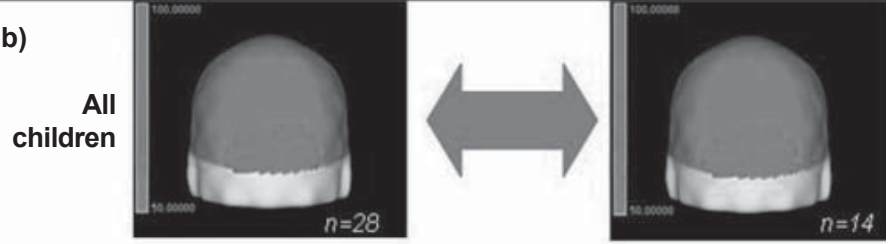

(n)

Permutation Overall Probability 0.52

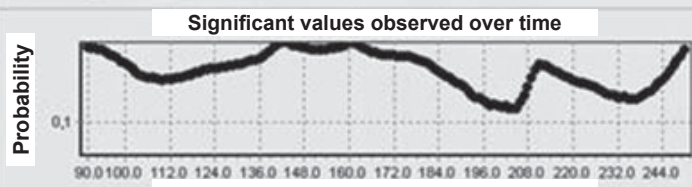
test results 90010001120124013601400160.01720184019602000250023202440 Milliseconds

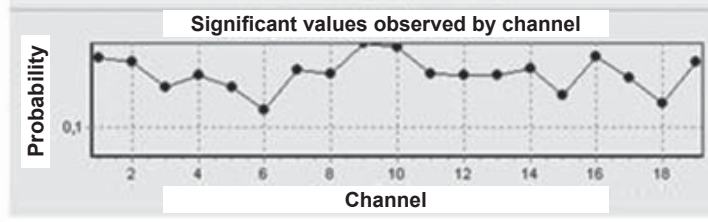

(available in color online at www.medicc.org/mediccreview/charroo-cross-modal.html)

Table 1: P1 amplitudes of flash VEP P1 peak in deaf and control children

\begin{tabular}{|l|l|l|l|l|l|l|}
\hline P1 Amplitude & Side & $\mathbf{n}$ & Minimum & Maximum & Mean & SD \\
\hline Deaf & Right & 14 & 1.31 & 4.11 & 2.80 & 0.77 \\
\hline Control & Left & 14 & 1.50 & 3.93 & 2.39 & 0.83 \\
\hline & Right & 28 & 1.57 & 4.49 & 2.85 & 1.02 \\
\hline & Left & 28 & 1.19 & 4.06 & 2.48 & 0.79
\end{tabular}

Permutation test:

Right hemisphere P1 amplitude (deaf vs. controls): $t=0.348 ; p=0.729$ Left hemisphere P1 amplitude (deaf vs. controls): $t=0.141 ; p=0.888$

moving dots. Furthermore, they studied adult subjects, since the visual task requires the subject's cooperation. These results suggest that deaf subjects perform differently than normal-hearing subjects due to preferential attention to objects appearing in the peripheral visual field.[1,3,4,6]

Our results found that in deaf children, other cortical areas do not activate when presented with simple visual stimuli-such as flashes of light - that do not require paying attention or performing a discrimination task during stimulus. Moreover, the children kept their eyes closed during visual stimulus presentation.

Our findings on flash stimulation in deaf children are one more piece of evidence among the dissimilar results on CMP in animal models that have been reported by several authors. For example, Rebillard et al.[25] described invasion of the primary auditory cortex from visual input in cats that experienced early destruction of their cochlear receptors. Furthermore, other authors report no evidence of activation of the primary auditory cortex in studies done on congenitally deaf cats subjected to visual stimuli.[26,27]

However, we consider our results valid, given that the pattern of flash VEP topography in individual and group maps for the control children is so regular. This concurs with reports by other authors, including evoked potential studies using other modalities; for example, median and tibial nerve SEP, $[18,28,29]$ and therefore, supports the technique's utility for assessing CMP in children with auditory sensory deprivation. Along these lines, it should be emphasized that from a practical point of view, evoked potentials are useful neurophysiological techniques for objectively assessing the functional state of the nervous system. Patient cooperation is not necessary (subjects only need to be relaxed and keep their eyes closed); they are easy to replicate among different laboratories; and their interpretation is based on patterns of normality obtained in healthy control groups, where trained personnel visually inspect the recordings and measures their peaks, and in the present study specifically, assess cortical response topography (peak or wave).

Furthermore, the study did demonstrate differences in SEP N20 topography between control and deaf children, specifically deaf children aged $\geq 7$ years, with long duration of deafness, since their deafness was prelingual and was detected at birth or under three months of age. In these children, evoked response was obtained in the region corresponding to hand representation in the somatosensory cortex contralateral to the stimulated median nerve. However, with right median nerve stimulation, this activation extended further, as activity was found in the left temporal region.

This study used a tactile stimulus appropriate to the somatosensory pathway, and the one most used in clinical practice for neurophysiological assessment of conduction in the dorsal column pathway. We interpret the change observed in SEP N20 topography as a neuroplastic phenomenon, cortical reorganization of somatosensory representation, an expression of CMP in that the temporal region that normally corresponds to auditory sensory input processing is activated in addition to the somatosensory cortical area for the hand.

Studies using vibrotactile stimulation have found increased tactile sensitivity in congenitally deaf persons and expansion of finger representation in blind braille readers.[30,31] Along these lines, over-representation of SEP N20 in the left hemisphere temporal region in deaf children aged $\geq 7$ years on right median nerve stimulation is a finding that in our opinion could be added to this evidence of CMP. The changes observed seem to be closely related to the flow of somatosensory input, resulting from a complex interaction among the effect of long duration of hearing loss, reliance on sign language for communication from an early age, and handedness. When observing the behavior of these children in the clinical neurophysiology laboratory while they were waiting to be seen, we could see that in general, they make considerable use of their hands to explore the environment, but hand use is greater when they communicate by sign language.

These results are evidence that changes observed in our laboratory in an earlier study of deaf-blind children are not exclusive to 
Figure 3: SEP N20 from median nerve electrical stimulation in a deaf child

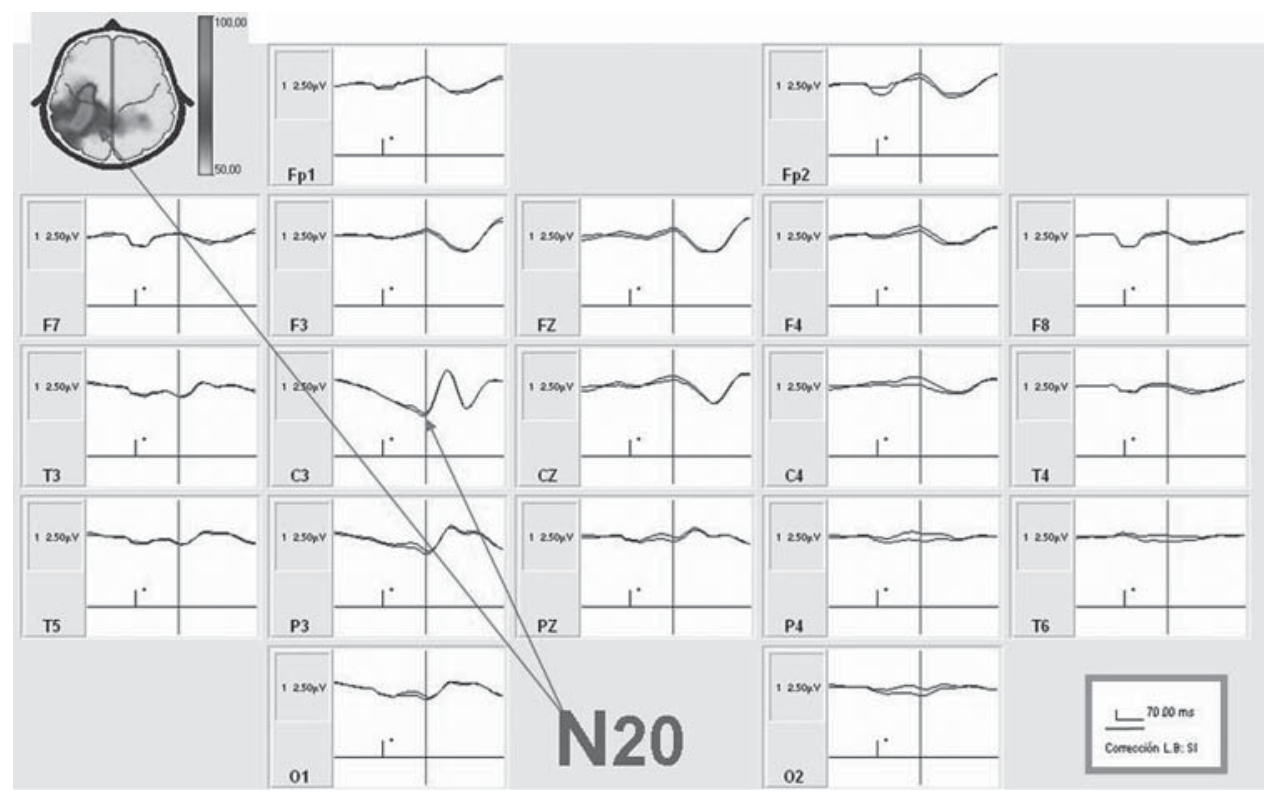

(available in color online at www.medicc.org/mediccreview/charroo-cross-modal.html)

Figure 4: SEP N20 median nerve topographic maps in deaf children (a) and permutation test results from comparing responses in children aged $\geq 7$ years and control group children (b)

\section{LEFT HEMISPHERE}

(a) Deaf Children

$>7$ years $n=6$

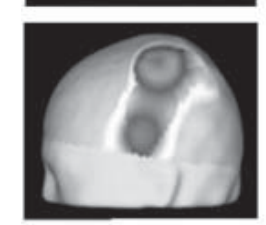

Control Group

(b) Children

$>7$ years
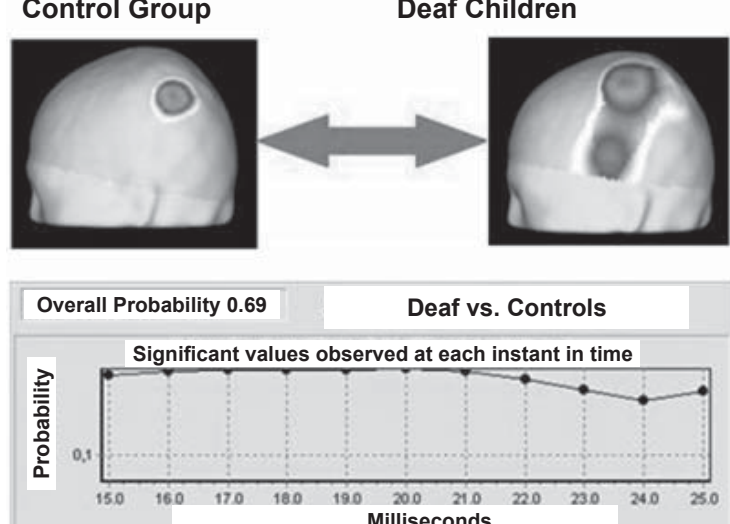

Permutation test results

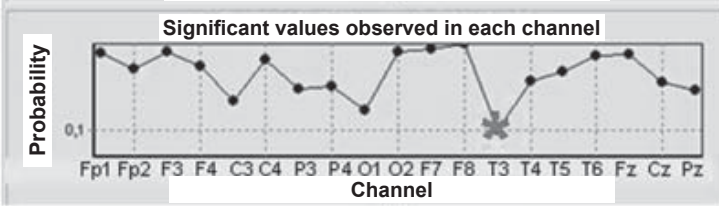

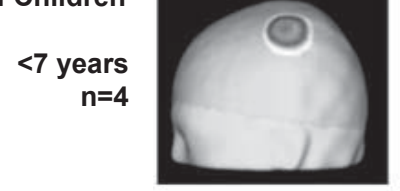

(available in color online at www.medicc.org/mediccreview/charroo-cross-modal.html) deaf-blindness but are also present in sighted deaf children. However, in deaf children, there was less asymmetry in left hemisphere SEP N20 response, since over-representation only extended to the temporal area, while in deaf-blind children, there was activation in parietal, temporal and occipital regions.[18] The first neurophysiological evidence of neuroplasticity that we described in deaf-blind $\mathrm{Cl}$ candidates corresponded to observations in a sample of deaf-blind children, which found a more extensive activation pattern in $\mathrm{fMRI}$ in response to tactile stimulation of the second and third fingers of the right hand.[32]

Studies of deaf children have demonstrated that $\mathrm{Cl}$ is less effective if the child is implanted late, a phenomenon that appears to be related at least in part to communication through sign language, because of cortical reorganization in the auditory cortex. In this situation, vision becomes the dominant sense.[15,33,34] even more so than in normal human development, in which approximately $80 \%$ of the brain is involved in processing visual information.[35]

However, our findings suggest that although vision is an extraordinarily important sense in humans, somatosensory information also plays an important role in deaf subjects, not only in deaf-blind subjects. We confirmed that somatosensory information invades the temporal cortical region as an expression of CMP in prelingually deaf children aged $\geq 7$ years, showing the implications of loss of the so-called critical period of neural development in deaf children who do not receive $\mathrm{Cl}$ early in life (before seven years of age, preferably before 3.5 years).[33,34] Quite the contrary: these children base their communication on sign language and, therefore, cortical somatosensory representation expands, particularly of the dominant hand in the contralateral hemisphere.

In summary, this study makes an important contribution to the field of deafness, neuroplasticity and $\mathrm{Cl}$ in deaf children, by showing that cortical reorganization takes place in somatosensory representation of the dominant hand, an expression of neuroplasticity due to cross-modal interaction between auditory and somatosensory sensory inputs. The question remains whether these finding might indicate that the greater the somatosensory reorganization, the less likely the child is to benefit from $\mathrm{Cl}$. To address this question, future studies will be necessary; accordingly, our working group plans to retest SEP N20 in these children after post$\mathrm{Cl}$ auditory rehabilitation.

\section{CONCLUSIONS}

This study yielded data on cortical processing of somatosensory information by deaf children, by assessing SEP N20 topography, where cortical over-representation of SEP 
$\mathrm{N} 20$ in the left temporal region is interpreted as evidence of CMP. This occurs if the deaf child does not receive $\mathrm{Cl}$ early in life and relies on sign language for communication; it is an important consideration in selecting children for $\mathrm{Cl}$ and a major ongoing issue in clinical practice among $\mathrm{Cl}$ specialists. Our finding that simple visual stimuli such as flashes of light only activate the occipital cortex in deaf persons, in contrast to stimuli that require visual attention, supports a preponderant role of somatesthetic input over purely visual in CMP in sighted deaf children, and further underscores the need for IC as early as possible.

\section{ACKNOWLEDGMENTS}

The authors are grateful to the Cuban Cochlear Implant Group and the institutions and agencies that support our work, as well as to the children served by the program and their parents, without whose help this study would not have been possible. -1 .

\section{REFERENCES}

1. Dye MW, Hauser PC, Bavelier D. Is visual selective attention in deaf individuals enhanced or deficient? The case of de useful field of view. PLoS One. 2009 May 20;4(5);e5640.

2. Finney EM, Clementz BA, Hickok G, Dobkins $\mathrm{KR}$. Visual stimuli activate auditory cortex in deaf subjects: evidence from MEG. Neuroreport. 2003 Aug 6;14(11):1425-7.

3. Finney EM, Fine I, Dobkins KR. Visual stimuli activate auditory cortex in the deaf. Nat Neurosci. $2001 \mathrm{Dec} ; 4(12): 1171-3$

4. Bavelier D, Tomann A, Hutton C, Mitchell T, Corina D, Liu G, et al. Visual attention to the periphery is enhanced in congenitally deaf individuals. J Neurosci. 2000 Sep 1;20(17):RC93.

5. Neville HJ, Schmidt A, Kutas M. Altered visualevoked potentials in congenitally deaf adults. Brain Res. 1983 Apr 25;266(1):127-32.

6. Neville HJ, Lawson D. Attentation to central and peripheral visual space in a movement detection task: an event-related potential and behavioural study. II. Congenitally deaf adults. Brain Res. 1987 Mar 10;405(2):268-83.

7. Meredith MA, Kryklywy J, McMillan AJ, Malhotra Sh, Lum-Tai R, Lomber SG. Crossmodal reorganization in the early deaf switches sensory, but not behavioral roles of auditory cortex. Proc Natl Acad Sci USA. 2011 May;108(21):8856-61.

8. Cohen LG, Celnik P, Pascual-Leone A, Corwell B, Falz L, Dambrosia J, et al. Functional relevance of cross-modal plasticity in blind humans. Nature 1997 Sep 11;389(6647):180-3.

9. Sherman C. Brain areas that serve specific functions for vision or hearing can take on a corresponding role for other senses in people who are blind or deaf. BrainWork. The Neuroscience Letter Winter 2011 [Internet]. New York: Dana's Foundation; 2011 [cited 2011 Oct 20]. 2 p. Available from: http://www.google.com.cu/url?sa=t\&r $\mathrm{ct}=\mathrm{j} \& \mathrm{q}=$ Brain+areas+that+serve+specific + functi ons+for+vision+or+hearing+can+take+on+a+co rresponding+role+for+other+senses+in+people +who+are+blind+or+deaf. $+\&$ source=web\&cd=1 \&ved=0CC4QFjAA\&url=http $\% 3 \mathrm{~A} \% 2 \mathrm{~F} \% 2 \mathrm{Fdana}$ .org\%2FuploadedFiles\%2FNews_and_Publicatio ns\%2FBrainWork\%2FBrainWork_Jan2011_Sen ses.pdf\&ei=Lem8UKiGFY2FyQHOmICgCQ\&usg =AFQjCNE5BSjwH_XZXe28R7P5PHF4OaOZIA

10. Sadato $N$, Yamada $H$, Okada $T$, Yoshida $M$, Hasegawa T, Matsuki K, et al. Age-dependent plasticity in the superior temporal sulcus in deaf humans: a functional MRI study. BMC Neurosci. 2004 Dec;8;5:56

11. Sadato $\mathrm{N}$, Okada $\mathrm{T}$, Honda $\mathrm{M}$, Yonekura $\mathrm{Y}$. Critical period for cross-modal plasticity in blind humans: a functional MRI study. Neuroimage. 2002 Jun; 16(2):389-400.

12. Sadato N, Pascual-Leone A, Gramfan J, Ibañez V, Deiber MP, Dold G, et al. Activation of the primary visual cortex by Braille reading in blind subjects. Nature. 1996 Apr 11;380(6574):526-8.

13. Newman AJ, Bavelier D, Corina D, Jezzard P, Neville HJ. A critical period for right hemisphere recruitment in American Sign Language processing. Nat Neurosci. 2002 Jan;5(1):76-80.
14. Bavelier D, Neville HJ. Cross-modal plasticity: where and how? Nature Rev Neurosci. 2002 Jun;3(6):443-52.

15. Bavelier D, Brozinsky C, Tomann A, Mitchell T, Neville H, Liu G. Impact of early deafness and early exposure to sign language on the cerebral organization for motion processing. J Neurosci. 2001 Nov 15;21(22):8931-42.

16. Neville HJ, Bavelier D, Corina D, Rauschecker J, Karni A, Lalwani A, et al. Cerebral organization for language in deaf and hearing subjects: Biological constraints and effects of experience. Proc Natl Acad Sci USA. 1998 Feb 3;95(3):9229.

17. Buckley KA, Tobey EA. Cross-modal plasticity and speech perception in pre- and postlingually deaf cochlear implant users. Ear Hear. 2010 Feb;32(1):2-15.

18. Charroó-Ruíz L, Pérez-Abalo MC, Hernández MC, Álvarez B, Bermejo B, Bermejo S, et al. Cross-modal plasticity in Cuban visuallyimpaired child cochlear implant candidates: topography of somatosensory evoked potentials. MEDICC Rev. 2012 Apr;14(2):23-9.

19. Charroó-Ruíz L, Aznielle T, Borrego M, Antelo JA, Díaz-Comas L, Suárez A, et al. Adquisición de la respuesta cortical del Potencial Evocado Somatosensorial del nervio tibial con múltiples derivaciones de registro. Rev Ing Electrónica, Automática y Comunicaciones 2005;16(2): 39-44. Spanish.

20. Charroó-Ruíz L, Hernández R, Pérez-Abalo M Machado C, Galán L, Aznielle T. Potenciales Evocados. Técnicas neurofisológicas y aplicaciones clínicas. Havana: Editorial Academia; 2001. p. 1-25, 77-114. Spanish.

21. Standards for short latency somatosensory evoked potentials. Milwaukee: American Clinica Neurophysiology Society; c2008. $13 p$

22. Díaz-Comas L, Borrego M, Bobes MA. Sistema para la obtención y análisis de Potenciales Evocados Endógenos de alta densidad. Memorias del I Congreso Internacional de Biolnformática 2004. Havana: [publisher unknown]; c2004. ISBN: 959237117 2. Spanish.

23. Chiappa KH, Hill RA. Principles of evoked potential. Short-latency somatosensory evoked potentials: Interpretation. In: Chiappa $\mathrm{KH}$, editor. Evoked Potentials in Clinical Medicine. 3rd ed. New York: Lippincott-Raven; 1997. p. 24-26, 341-400.

24. Galán L, Biscay R, Rodriguez JL, Pérez-Abalo MC, Rodríguez R. Testing topographic differences between event related brain potentials by using non-parametric combinations of permutation tests. Electroencephalogr Clin Neurophysiol. 1997 Mar;102(3):240-7.

25. Rebillard G, Rebillard M, Pujol R. Factors affecting the recording of visual-evoked potentials from the deaf cat primary auditory cortex (Al). Brain Res. 1980 Apr 21;188(1):252-4

26. Kral A, Schröder JH, Klinke R, Engel AK Absence off cross-modal reorganization in the primary auditory cortex of congenitally deaf cats. Exp Brain Res. 2003 Dec;153(4):605-13.
27. Stewart DL, Starr A. Absence of visually influenced cells in auditory cortex of normal and congenitally deaf cats. Exp Neurol. 1970 Sep;28(3):525-8.

28. Kakigi R, Shibasaki H. Effects of age, gender and stimulus side on the scalp topography of somatosensory evoked potentials following median nerve stimulation. J Clin Neurophysiol. $1991 \mathrm{Jul} ; 8(3): 320-30$.

29. Kakigi R, Shibasaki H. Effects of age, gender, and stimulus side on the scalp topography of somatosensory evoked potentials following posterior tibial nerve stimulation. J Clin Neurophysiol. 1992 Jul;9(3):431-40.

30. Levänen S, Hamdorf D. Feeling vibrations: enhanced tactile sensitivity in congenitally deaf humans. Neurosci Lett. 2001 Mar 23;301(1):75-7.

31. Auer ET Jr, Bernstein LE, Sungkarat W, Singh M. Vibrotactile activation of the auditory cortices in deaf versus hearing adults. Neuroreport. 2007 May 7:18(7):645-8.

32. Valdés M, Rodríguez V, Charroó L. Cortical Brain Plasticity in deaf-blind children. Proceedings of the XIX IERASG BIENNIAL SYMPOSIUM; 2005; Granada, Spain

33. Sharma A, Dorman MF, Kral A. The influence of a sensitive period on central auditory development in children with unilateral and bilateral cochlear implants. Hear Res. 2005 May;203(1-2):134-43.

34. Sharma A, Dorman MF, Spahr AJ. A sensitive period for the development of the central auditory system in children with cochlear implants: implications for age of implantation. Ear Hear. 2002 Dec;23(6):532-9.

35. Malkowicz DE, Myers G, Leisman G. Rehabilitation of cortical visual impairment in children. Int $J$ Neurosci. 2006 Sep;116(9):1015-33

\section{THE AUTHORS}

Lidia E. Charroó-Ruíz (Corresponding author: lidia@cneuro.edu.cu), clinical neurophysiologist. Associate professor, Cuban Neuroscience Center (CNC), Havana, Cuba.

Thais Picó Bergantiños, physician specializing in histology with a master's degree in neurosciences, Havana School of Dentistry, Cuba.

María C. Pérez-Abalo, clinical neurophysiologist, CNC, Havana, Cuba.

María del Carmen Hernández Cordero, clinical neurophysiologist, CNC, Havana, Cuba.

Sandra Bermejo Guerra, ear, nose and throat specialist Hearing Center, Marfán Pediatric Teaching Hospital, Havana, Cuba.

Beatriz Bermejo Guerra, speech therapist and speech pathologist, La Pradera International Health Clinic, Havana, Cuba. 
Beatriz Álvarez Rivero, ophthalmologist, Marfán Pediatric Teaching Hospital, Havana, Cuba.

Antonio S. Paz Cordovés, ear, nose and throat specialist and cochlear implant surgeon, Hermanos Ameijeiras Clinical-Surgical Teaching Hospital Cochlear Implant Group, Havana, Cuba.

Ulises Rodríguez Morales, ear, nose and throat specialist and cochlear implant surgeon,
Marfán Pediatric Teaching Hospital Cochlear Implant Group, Havana, Cuba.

Manuel E. Sevila Salas, ear, nose and throat specialist and cochlear implant surgeon, Hermanos Ameijeiras Clinical-Surgical Teaching Hospital Cochlear Implant Group, Havana, Cuba.

Yesi Martínez García, scrub nurse, Marfán Pediatric Teaching Hospital Implant Group, Havana, Cuba.
Lídice Galán García, mathematician with a doctorate in health sciences, CNC, Havana, Cuba.

Submitted: February 7, 2012

Approved for publication: January 20, 2013 Disclosures: None

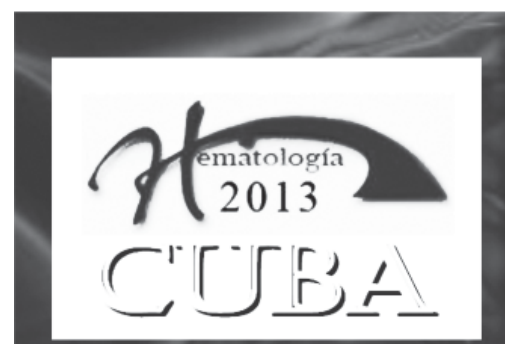

IX Latinamerican Meeting on Hematology, Immunology and Transfusion Medicine

IV International Workshop on Hemophilia

III International Symposium on Regenerative Medicine

VII Cuban Congress of Hematology

May 20-24, 2013 - Havana International Convention Center

\section{Congress themes:}

$\checkmark$ Leukemias and other malignant hemopathies

$\checkmark$ Stem cell transplantation and regenerative medicine

$\checkmark$ Hemophilias and other coagulation disorders

$\checkmark$ Immunodeficiencies and other immunological disorders

$\checkmark$ Immunohematology

$\checkmark$ Transfusion medicine, blood bank organization and blood safety

Conference language: Spanish (oral and poster presentations may be in English; translation provided for some sessions)

Hosts: Cuban Society of Hematology, Hematology and Immunology Institute

Contact: hematologia2013@infomed.sId.cu

http://hematologia2013.sld.cu http://www.hematologiacuba.com

US Government restrictions may apply to US participants 